\title{
Asymmetrical slip propensity: required coefficient of friction
}

\author{
Jung-suk Seo ${ }^{1}$ and Sukwon Kim²
}

\begin{abstract}
Background: Most studies in performing slips and falls research reported their results after the ipsilateral leg of subjects (either right foot or left foot) was guided to contact the contaminated floor surface although many studies indicated concerns for asymmetries of legs in kinematic or kinetic variables. Thus, the present study evaluated if dominant leg's slip tendency would be different from non-dominant leg's slip tendency by comparing the Required Coefficient of Friction (RCOF) of the two lower limbs.

Findings: Forty seven health adults participated in the present study. RCOF was measured when left or right foot of subjects contacted the force platforms respectively. Paired t-test was performed to test if RCOF and heel velocity $(\mathrm{HCV})$ of dominant legs was different from that of non-dominant legs. It was suggested that the asymmetry in RCOFs and HCV between the two lower limbs existed. The RCOFs of non-dominant legs were higher than that of dominant legs.

Conclusions: The results indicated that asymmetry in slip propensity, RCOF, was existed in lower extremity. The results from the study suggested that it would be benefit to include a variable, such as asymmetry, in slips and falls research.
\end{abstract}

Keywords: Gait asymmetry, RCOF, Slip propensity, Limb asymmetry, Gait kinetics

\section{Findings} Introduction

Many studies have attempted to find mechanisms in association with slip-induced fall accidents. In most of these studies, 1) experimental protocols that mimicked slips were included and 2) characteristics of either right or left lower limbs while it was striking the floor materials were reported. Particularly, studies introduced postural perturbations while the subjects' right foot was landing on the surface [1-8], whereas, another studies introduced perturbations while the subjects' left foot was landing [9-11]. In addition, Gronqvist et al. [12] provided perturbations to either left or right lower limb when it was striking the floor.

RCOF (Required Coefficient of Friction) represents the minimum coefficient of friction that must be available at the shoe-floor interface to present slip initiation. RCOF was determined by the ratio of vertical ground reaction

\footnotetext{
* Correspondence: rockwall@jbnu.ac.kr

${ }^{2}$ Department of Physical Education, College of Education, Chonbuk National University, Jeonju-si, Jeollabuk-do, South Korea

Full list of author information is available at the end of the article
}

force over horizontal ground reaction force [13] during heel contact phase of gait cycle. Assuming that the RCOF from the two lower limbs were different, one could expect that measuring the RCOF of the right lower limb in one study would produce different results than studies that measure the RCOF of the left lower limb of the same subjects.

Dangerous slips are most likely to occur when RCOF at the shoe-floor interface exceeds the available coefficient of friction (ACOF) of the floor. Slip severity would increase as the difference between the RCOF and available dynamic COF of the floor surface increases $[14,15]$. It was suggested that lower limbs of healthy people with no injury behave asymmetrically while walking [16]. Studies suggested asymmetrical spatial-temporal and kinematic behaviors between dominant legs and non-dominant legs [17-20]. The present study hypothesized that slip tendencies of the two lower limbs would be different.

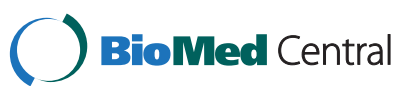




\section{Methods}

Forty seven healthy adults (20 females and 27 males, ages between $21-70$ years old, $169.6 \pm 7.8 \mathrm{~cm}$, BMI of $25.9 \pm 4.3)$ participated in this study. Some volunteers were excluded if they reported any physical problems affecting their walking. Each participant completed an inform consent procedure approved by the university's Internal Review Board (IRB). Walking trials were conducted on a walking track $(20 \mathrm{~m})$, which elevated $15 \mathrm{~cm}$ above the floor surface (Figure 1, adapted from [21]). Two force plates (BERTEC \# K80102, TYPE 45550-08) covered by the vinyl tile were used to collect ground reaction forces at $1200 \mathrm{~Hz}$. The recoding area was about.

Each participant was asked to walk at his or her preferred walking speed. They were asked to walk freely and their start points at each end were adjusted until their walking was consistent throughout their test time. This allowed his or her left foot landed on the first force plate and the right foot landed on the second force plate in a row. For every participant, one RCOF of left heel contact was collected from the first force platform (F1 in Figure 1) and one RCOF of right heel contact was collected from the second force platform (F2 in Figure 1). Their kicking legs (soccer ball) were considered for dominant legs. There were only 2 participants who indicated their left leg for kicking leg.

The difference in RCOF and HCV of dominant leg and non-dominant leg was evaluated using paired t-tests (SPSS 12.0). The results were considered as statistically significant when $\mathrm{p} \leq 0.01$. Table 1 compares mean and standard deviation of the RCOF in dominant (initial as "D") and non-dominant (initial as "N") legs. Paired-t test indicated that $\mathrm{RCOF}(\mathrm{t}=4.61,46, \mathrm{P}<0.0001)$ was statistically higher in dominant leg, $\mathrm{HCV}(\mathrm{t}=12.24,46, \mathrm{P}<$
Table 1 Descriptive statistics of RCOF, HCV, and TA COM

\begin{tabular}{llll}
\hline & RCOF & HCV(cm/s) & TA COM(cm/s2) \\
\hline $\mathrm{D}$ & $0.176 \pm 0.032$ & $217.9 \pm 57.34$ & $137.12 \pm 531.36$ \\
$\mathrm{~N}$ & $0.193 \pm 0.034$ & $107.42 \pm 44.77$ & $157.92 \pm 513.73$ \\
\hline
\end{tabular}

0.0001) was statistically faster in non-dominant leg, and TA COM ( $\mathrm{t}=3.21,46, \mathrm{P}=0.0001)$.

\section{Discussion}

Changes in either vertical forces or horizontal forces may alter RCOF. Horizontal heel velocity (i.e. HCV) and forward acceleration of the whole body center of mass (TA COM) have been thought to increase the RCOF due to their effects on the variation in the horizontal force component $[1,15,22]$.

One of principal actions of lower extremity muscles is to accelerate and to decelerate angular motions of the legs when walking [23] and Rice and Seeley [24] suggested that the non-dominant lower limb contributed more to support impulse (upward acceleration of COM), while the dominant limb contributed more to propulsion impulse (forward acceleration of COM) when walking fast. In the present study, higher RCOFs were found when the non-dominant legs were contacting the floor surface. Faster forward acceleration of the center of mass by the dominant lower limb could have resulted higher RCOF. By Newton's $1^{\text {st }}$ law, acceleration profiles affects ground reaction force production since a person's mass is constant. Faster TA COM could contribute to a relatively larger increase in horizontal ground reaction forces than vertical ground reaction forces resulting in higher RCOF. It was suggested that, when heel contact velocity was minimized to zero, the body traveled forward from

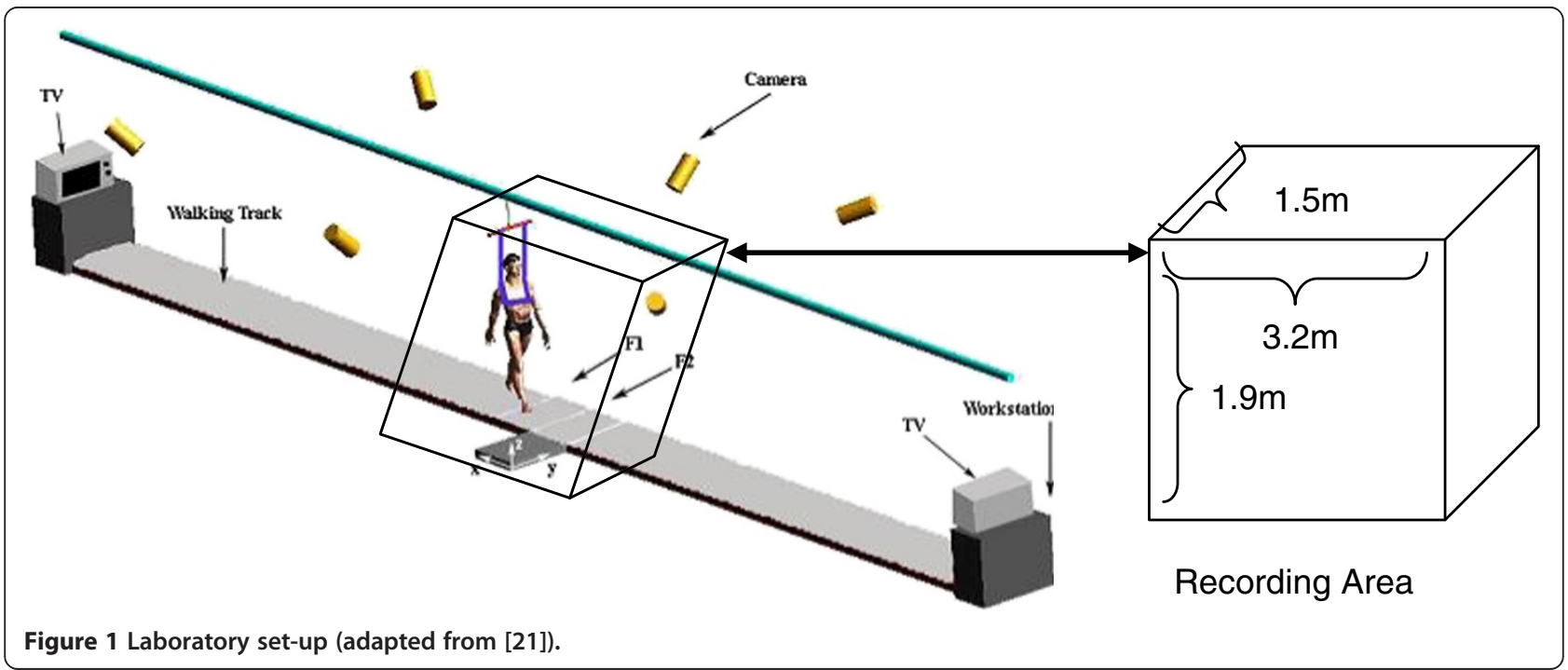


one point to the other point in order to maintain forward body momentum $[1,15]$. As the stance limb prepares to leave the ground, the contralateral limb contacts ground and accepts the body's forward momentum. As a result, the imposed horizontal force relative to vertical force could increase more at shoe-floor interface as the whole body COM travelled forward rapidly [1] contributing to an increase in RCOF when non-dominant leg was contacting the floor surface and the body was transitioning over non-dominant legs (i.e. ratio of horizontal force to vertical force).

In previous studies [22], faster heel contact velocity was suggested to increase RCOF, thus, the likelihood of slip-induced falls. Therefore, heel contact velocity may be one of factors contributing to a risk of slip-induced falls among the elderly [22]; Mills and Barrett [25]. However, the majority of slips and slip-induced falls were likely to occur $50-80 \mathrm{~ms}$ after heel contacted the ground (i.e. RCOF occurs at about $70 \mathrm{~ms}$ after heel contact) $[1,4]$. Accordingly, the suggestions by Winter et al. [22], and Mills and Barrett [25] should not be significant since heel velocity right after heel contact should be minimized almost to zero [1]. Thus, it may be unconvincing to suggest that RCOF, which occurs $70-120 \mathrm{~ms}$ after heel contact, may directly be related to the heel contact velocity.

Several studies suggested that as differences between the friction demand characteristic (i.e., RCOF) and available dynamic COF increased, the number of slip events would increase $[13,14]$. Dangerous slips occurred when the friction force opposing the movement of the foot was less than the shear force of the foot shortly after the heel contacted the ground $[1,4,14]$. Given the constant contact time and mass associated with heel contact of the gait cycle [26], the impulse-momentum relationship indicates that horizontal shear force increases more as the differences of the whole body COM velocity became larger. If the push-off forces of dominant legs were larger propelling the whole body COM faster, the horizontal shear force produced at the shoe-floor interface became larger proportionally, resulting in a larger RCOF of non-dominant limb.

The statistical differences in RCOF of the two limbs seen in the present study suggested that the previous studies $[2,5,7,9-12,27]$ could come to different conclusions just because of kinematics of the two limbs. In addition, asymmetrical strength of the two legs [28-30], especially greater asymmetry in older adults [29], could influence kinematics of the either striking leg or supporting leg (rear leg). The leg strength and/or power was correlated to fall risk; fallers generated less leg strength or power [29,31-33] because the ability to generate an adequate neural response, thus, the power in muscles would be a key factor in producing movement and its control $[4,29]$. By analyzing the kinematic data, it is easily seen that the slipping leg would extend at knee joint while the support leg (real leg) would flex at knee joint. Hamstring muscle of slipping leg and rectus femoris muscle of rear leg should produce adequate eccentric contraction at knee joints in order to stop hyperextension of slipping leg or hyperflexion of supporting leg (i.e. out of normal range during walking) at knee joints. Without the proper generation of muscle power, a person would fall. Particularly, older adults showed difficulty in controlling activities when a strong eccentric component was required [34]. The asymmetrical eccentric strength could influence the likelihood of slip-induced falls, especially, in older adults.

In conclusion, measuring or evaluating the kinematics and kinetics of just one leg would have some limitations in making statements about the likelihood of slips and falls. Some people with greater asymmetry in lower extremity would exhibit a significant difference in the likelihood of slips and falls between the two legs. This would result in a significantly different outcome when interpreting data. Finally, there would be a substantial advantage if studies in regard to the slips and falls should consider including the variable, such as asymmetry.

\section{Competing interests}

The authors declare that they have no competing interests.

\section{Authors' contribution}

SK and JS have made contributions to interpretation of data. SK and JS have been involved in drafting and revising the manuscript, and analyzing data. SK has been involved in acquisition of data, and development of conception. All authors read and approved the final manuscript.

\section{Author details}

${ }^{1}$ Division of Sports Science, College of Natural Science, WonKwang University, Iksan-si, Jeollabuk-do, South Korea. ${ }^{2}$ Department of Physical Education, College of Education, Chonbuk National University, Jeonju-si, Jeollabuk-do, South Korea.

Received: 2 August 2012 Accepted: 26 July 2013

Published: 31 July 2013

\section{Reference}

1. Kim SW, Lockhart T, Yoon H: Relationship between age-related gait adaptations and required coefficient of friction. Saf Sci 2005, 43:425-436.

2. Kim S, Lockhart TE: The Effects of $10 \%$ Front Load Carriage on the Likelihood of Slips and Falls. Ind Health 2008, 46:32-39.

3. Liu J, Lockhart TE: Age-related joint moment characteristics during normal gait and successful reactive recovery from unexpected slip perturbations. Gait Posture 2009, 30:276-281.

4. Lockhart TE, Kim SW: Relationship Between Hamstring Activation Rate and Heel Contact Velocity: Factors Influencing Age-Related Slip-Induced Falls. Gait Posture 2006, 24(1):23-34.

5. Marigold D, Patla A: Strategies for dynamic stability during locomotion on a slippery surface: effects of prior experience and knowledge. J Neurophysiol 2002, 88:339-353.

6. Marigold D, Bethune A, Patla A: Role of the unperturbed limb and arms in the reactive recovery response to an unexpected slip during locomotion. J Neurophysioloyg 2003, 89:1727-1737.

7. Menant J, Steele J, Menz H, Munro B, Lord S: Rapid gait termination: effects of age, walking surfaces and footwear characteristics. Gait Posture 2009, 30:65-70.

8. Parijat P, Lockhart TE: Effects of lower extremity muscle fatigue on the outcomes of slip-induced falls. Ergonomics 2008, 51(12):1873-1884. 
9. Cham R, Redfern M: Lower extremity corrective reactions to slip events. J Biomech 2001, 34:1439-1445.

10. Cham R, Redfern M: Heel contact dynamics during slip events on level and inclined surfaces. Saf Sci 2002, 40:559-576.

11. Cham R, Redfern M: Changes in gait when anticipating slippery floors. Gait Posture 2002, 15:159-171.

12. Gronqvist R, Hirvonen M, Rajamaki E, Matz S: The validity and reliability of a portable slip meter for determining floor slipperiness during simulated heel strike. Accid Anal Prev 2003, 35:211-225.

13. Redfern $M$, Andres $R$ : The analysis of dynamic pushing and pulling; required coefficients of friction. Toronto, Ont. 1984: Proceedings of the 1984 International Conference on Occupational Ergonomics; 1984.

14. Hanson JP, Redfern MS, Mazumdar M: Predicting slips and falls considering required and available friction. Ergonomics 1999, 42(12):1619-1633.

15. Lockhart T, Woldstad J, Smith J: Effects of age-related gait changes on the biomechanics of slips and falls. Ergonomics 2003, 46(12):1136-1160.

16. Sadeghi $H$, Allard $P$, Prince $F$, Labelle $H$ : Symmetry and limb dominance in able-bodies gait: a review. Gait Posture 2000, 12:34-45.

17. Allard P, Lachance R, Aissaoui R, Duhaime M: Simultaneous bilateral 3-D able-bodied gait. Hum Mov Sci 1996, 15:327-346.

18. Barr A, Andersen JC, Danoff JV, et al: Symmetry of temporal. Bethesda, MD: Spatial and kinematic events during gait. Read at the Third Annual East Coast Gait Laboratory Conference; 1987.

19. Law HT: Microcomputer-based, low cost method for measurement of spatial and temporal parameters of gait. J Biomed Eng 1987, 9(2):115-120

20. Rosenrot P, Wall JC, Charteris J: The relationship between velocity, stride time, support time and swing time during normal walking. J Hum Mov Stud 1980, 6:323-335.

21. Kim SW, Lockhart T: Lower limb control and mobility following exercise training. JNER 2012, 9:15

22. Winter D, Patla A, Frank J, Walt S: Biomechanical walking pattern changes in the fit and healthy elderly. Phys Ther 1990, 70:340-347.

23. Seeley MK, Umberger BR, Shapiro R: A test of the functional asymmetry hypothesis in walking. Gait and Posture 2008, 28(1):24-28.

24. Rice J, Seeley M: An investigation of lower-extremity functional asymmetry for non-preferred able-bodied walking speeds. Int J Exerc Sci 2010, 3(4). Article 4.

25. Mills $P$, Barrett R: Swing phase mechanics of healthy young and elderly men. Hum Mov Sci 2001, 20:427-446.

26. Irvine C: Evaluation of the effect of contact-time when measuring floor slip resistance. J Test Eval 1986, 1:19-22.

27. Mahboobin A, Cham R, Piazza S: The impact of a systematic reduction in shoe-floor friction on heel contact walking kinematics- A gait simulation approach. J Biomech 2010, 43(8):1532-1539.

28. Knapik J, Bauman C, Jones B, Harris J, Vaughan L: Preseason strength and flexibility imbalances associated with athletic injuries in female collegiate athletes. Am J Sports Med 1991, 19:76-81.

29. Perry M, Carville S, Smith C, Rutherford O, Newham D: Strength, power output and symmetry of leg muscles: effect of age and history of falling. Eur J Appl Physiol 2007, 100:553-561.

30. Skelton D, Kennedy J, Rutherford O: Explosive power and asymmetry in leg muscle function in frequent fallers and non-fallers aged over 65 . Age Ageing 2002, 31(2):119-125.

31. Kenny RA, Rubenstein LZ, Martin FC, Tinetti ME: Guideline for the prevention of falls in older persons. J Am Geriatr Soc 2001, 49:664-672.

32. Robinson B, Gordon J, Wallentine S, Visio M: Relationship between lower-extremity joint torque and the risk for falls in a group of community-dwelling older adults. Physiother Theory Pract 2004, 20:155-173.

33. Takazawa K, Arisawa K, Honda S, Shibata Y, Saito H: Lower-extremity muscle forces measured by a hand-held dynamometer and the risk of falls among day-care users in Japan: using multinomial logistic regression analysis. Disabil Rehabil 2003, 25:399-404.

34. Lark S, Buckley J, Bennett S, Jones D, Sargeant A: Joint torques and dynamic joint stiVness in elderly and young men during stepping down. Clin Biomech 2003, 18:848-855.

doi:10.1186/1743-0003-10-84

Cite this article as: Seo and Kim: Asymmetrical slip propensity: required coefficient of friction. Journal of NeuroEngineering and Rehabilitation 2013 10:84.

\section{Submit your next manuscript to BioMed Central and take full advantage of:}

- Convenient online submission

- Thorough peer review

- No space constraints or color figure charges

- Immediate publication on acceptance

- Inclusion in PubMed, CAS, Scopus and Google Scholar

- Research which is freely available for redistribution 